\title{
Altered levels of AtHSCB disrupts iron translocation from roots to shoots
}

\author{
Laura Leaden $^{1,2} \cdot$ María A. Pagani $^{1} \cdot$ Manuel Balparda $^{1} \cdot$ María V. Busi $^{1} \cdot$ \\ Diego F. Gomez-Casati ${ }^{1}$
}

Received: 6 November 2015 / Accepted: 29 August 2016

(C) Springer Science+Business Media Dordrecht 2016

\begin{abstract}
Key message Plants overexpressing AtHSCB and hscb knockdown mutants showed altered iron homeostasis. The overexpression of AtHSCB led to activation of the iron uptake system and iron accumulation in roots without concomitant transport to shoots, resulting in reduced iron content in the aerial parts of plants. By contrast, hscb knockdown mutants presented the opposite phenotype, with iron accumulation in shoots despite the reduced levels of iron uptake in roots. AtHSCB play a key role in iron metabolism, probably taking part in the control of iron translocation from roots to shoots.

Abstract Many aspects of plant iron metabolism remain obscure. The most known and studied homeostatic mechanism is the control of iron uptake in the roots by shoots. Nevertheless, this mechanism likely involves various unknown sensors and unidentified signals sent from one tissue to
\end{abstract}

Laura Leaden, María A. Pagani and Manuel Balparda contributed equally to this work.

Electronic supplementary material The online version of this article (doi:10.1007/s11103-016-0537-9) contains supplementary material, which is available to authorized users.

María A. Pagani

pagani@cefobi-conicet.gov.ar

$\triangle$ Diego F. Gomez-Casati

gomezcasati@cefobi-conicet.gov.ar

1 Centro de Estudios Fotosintéticos y Bioquímicos (CEFOBI), CONICET - Universidad Nacional de Rosario, Suipacha 531, 2000 Rosario, Argentina

2 Present address: Departamento de Microbiologia, Instituto de Ciências Biomédicas, Universidade de São Paulo, Av. Prof. Lineu Prestes 1374, São Paulo 05508-900, Brazil another which need to be identified. Here, we characterized Arabidopsis thaliana plants overexpressing AtHSCB, encoding a mitochondrial cochaperone involved in [Fe-S] cluster biosynthesis, and hscb knockdown mutants, which exhibit altered shoot/root Fe partitioning. Overexpression of AtHSCB induced an increase in root iron uptake and content along with iron deficiency in shoots. Conversely, $h s c b$ knockdown mutants exhibited increased iron accumulation in shoots and reduced iron uptake in roots. Different experiments, including foliar iron application, citrate supplementation and iron deficiency treatment, indicate that the shootdirected control of iron uptake in roots functions properly in these lines, implying that $[\mathrm{Fe}-\mathrm{S}]$ clusters are not involved in this regulatory mechanism. The most likely explanation is that both lines have altered Fe transport from roots to shoots. This could be consistent with a defect in a homeostatic mechanism operating at the root-to-shoot translocation level, which would be independent of the shoot control over root iron deficiency responses. In summary, the phenotypes of these plants indicate that AtHSCB plays a role in iron metabolism.

Keywords Iron · AtHSCB - Iron partitioning · Arabidopsis thaliana

\section{Introduction}

Iron-sulphur clusters are amongst the simplest cofactors used by (almost) all living organisms. These clusters are implicated in a myriad of vital processes such as respiration, photosynthesis, sulphur and nitrogen assimilation, amino acid and purine metabolism, plant hormone and coenzyme biosynthesis and DNA repair and translation, among others (Balk and Pilon 2011; Lill 2009). Although clusters can 
be synthesized non-enzymatically in vitro (Beinert 2000), their biosynthesis is catalyzed by specific enzymes. In bacteria, three complete [Fe-S] biogenesis systems have been discovered, i.e., NIF (nitrogen fixation), SUF (mobilization

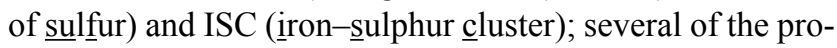
teins in these systems are encoded by operons. The genes comprising the isc operon are conserved and widely distributed, and homologues of the isc components are found in the mitochondria of yeast and higher eukaryotes (Balk and Lobreaux 2005; Muhlenhoff and Lill 2000).

In yeast mitochondria, the release of sulphur from cysteine is catalyzed by the cysteine desulphurase Nfs1, and sulphur is transferred to the scaffold protein Isu1, where the iron-sulphur clusters are assembled (Balk and Lobreaux 2005; Balk and Pilon 2011; Johnson et al. 2005). The nature of the iron source is still under debate, although in several organisms, such as E. coli, S. cerevisiae and H. sapiens, there is substantial evidence pointing towards frataxin (Yfh1) (Stemmler et al. 2010), a protein that also appears to have a regulatory effect on the ISC pathway (Pastore and Puccio 2013). In the last stage of this pathway, in a process specifically assisted by a dedicated chaperone system comprising the Hsp70 ATPase Ssq1 and the specialized DnaJ-like cochaperone Jac1 (Cupp-Vickery et al. 2004; Dutkiewicz et al. 2004) among other additional factors, the mature $[\mathrm{Fe}-\mathrm{S}]$ cluster is transferred and inserted into apoproteins. This complex formation is thought to induce a structural change in Isu1, thereby weakening Fe-S-cluster binding, thus facilitating cluster dissociation and transfer to apoproteins (Bonomi et al. 2008; Lill 2009; Markley et al. 2013).

In Arabidopsis thaliana plants, frataxin (AtFH) and cysteine desulphurase (AtNFS1) homologues are thought to be involved in early steps of Fe-S cluster formation in mitochondria, specifically iron loading and sulphur transfer to the scaffold proteins (Gerber et al. 2003). We previously characterized the Arabidopsis frataxin homologue and demonstrated that it is essential for full activity of mitochondrial $[\mathrm{Fe}-\mathrm{S}]$ proteins and hemeproteins (Busi and Gomez-Casati 2012; Busi et al. 2004, 2006; Maliandi et al. 2011) and that it participates in the Fe-mediated oxidative stress response (Maliandi et al. 2007; Martin et al. 2009). In addition, we recently reported that AtNFS1 interacts with AtFH and that this interaction modulates the kinetic properties of the former protein (Turowski et al. 2012). These findings indicate that AtFH plays a direct role in regulating mitochondrial cysteine desulphurase activity and that both proteins function in early steps of [Fe-S] cluster biogenesis (Busi and Gomez-Casati 2012; Busi et al. 2006; Turowski et al. 2012). The second stage of the $[\mathrm{Fe}-\mathrm{S}]$ cluster assembly pathway in plant mitochondria likely resembles that of yeast mitochondria, involving the transfer of the nascent cluster from AtISU1 to the target proteins, probably mediated by the chaperone/cochaperone system AtHSCA1-2/AtHSCB. In addition, the cochaperone AtHSCB from Arabidopsis can functionally complement the yeast $j a c 1$ knockout mutant, suggesting that AtHSCB plays a role in $[\mathrm{Fe}-\mathrm{S}]$ cluster biogenesis in plants. Furthermore, an AtHSCB T-DNA insertion mutant shows reduced seed set and abnormal trichome development, as well as dramatically reduced activities of the $[\mathrm{Fe}-\mathrm{S}]$ enzymes aconitase (ACO) and succinate dehydrogenase (SDH) (Xu et al. 2009). Moreover, we previously demonstrated that AtHSCB can physically interact with AtISU1 and AtHSCA2, providing more evidence for its involvement in the biosynthesis of [ $\mathrm{Fe}-\mathrm{S}]$ clusters in plants (Leaden et al. 2014). However, to date, little is known about the in vivo function of the cochaperone AtHSCB in plants. Nevertheless, HSC20, the human AtHSCB homologue, has been shown to physically interact with a specific subset of recipient $[\mathrm{Fe}-\mathrm{S}]$ proteins, such as SDHB (the complex II $[\mathrm{Fe}-\mathrm{S}]$ subunit) and other accessory factors that assist cluster delivery through their tripeptide LYR motif, whose presence appears to be the basis for substrate discrimination (Maio et al. 2014).

Iron-sulphur biogenesis represents an important sink for iron in living organisms. Plants have to acquire this metal from soils where, although abundant, it usually has very low bioavailability. To cope with this problem, dicots and nongraminaceous monocots utilize strategy I for iron uptake, which involves proton extrusion to solubilize $\mathrm{Fe}^{3+}$ in the soil, reduction of $\mathrm{Fe}^{3+}$ to $\mathrm{Fe}^{2+}$ and transport of $\mathrm{Fe}^{2+}$ across the root epidermal cell membrane. In Arabidopsis, a member of $\mathrm{H}^{+}$-ATPase family (AHA2) likely mediates proton efflux (Santi and Schmidt 2009), the ferric-chelate reductase oxidase 2 (FRO2) is responsible for the reduction of $\mathrm{Fe}^{3+}$ (Robinson et al. 1999) and there is ample evidence that the iron regulated transporter 1 (IRT1) transports $\mathrm{Fe}^{2+}$ into root cells (Barberon et al. 2011; Connolly et al. 2003; Eide et al. 1996). To acquire enough Fe while avoiding toxicity, Fe uptake in non-graminaceous plants is tightly controlled (Vert et al. 2002; Yi and Guerinot 1996). The key regulator of root iron acquisition in strategy I plants, FIT, plays crucial roles in positively regulating $F R O 2$ and IRT1 under Fe deficiency (Colangelo and Guerinot 2004; Jakoby et al. 2004), in conjunction with two other basic helix-loop-helix transcription factors (bHLH38 and bHLH39) (Yuan et al. 2008). Recently, in Arabidopsis it has been described an ATP-binding cassette transporter ABCG37 (alias PDR9) that is involved in secretion of phenolic compounds from roots into the medium in response to Fe deficiency, indicating the presence of a secondary strategy to Fe uptake in non-graminaceous plants (Fourcroy et al. 2014; RodriguezCelma and Schmidt 2013). In contrast to the abundant data on root iron uptake and its regulation, little is known about Fe transport to the shoot, remobilization and distribution in different tissues and subcellular translocation and storage. 
Three proteins that are clearly involved in iron transport are the nicotianamine synthase NAS4 (Koen et al. 2013), the citrate transporter FRD3 (Rogers and Guerinot 2002) and the xylem iron transporter FPN1 (Morrissey et al. 2009). While considerable progress has been made over the past few years in elucidating the mechanism underlying iron transport, some of the key components of iron metabolism that are yet to be deciphered include (i) the full set of transcription factors that regulate and fine-tune iron homeostasis, (ii) the precise mechanisms and transporters involved in transport into and out of xylem and phloem vessels and (iii) signals and receptors (sensors) that regulate Fe nutritional status (Darbani et al. 2013; Hindt and Guerinot 1823; Ivanov et al. 2012; Vigani et al. 2013).

Evidence suggests that there is an intimate connection between $\mathrm{Fe}$ homeostasis and $[\mathrm{Fe}-\mathrm{S}]$ cluster biosynthesis. Fungi, fruit flies, mice and animal cells that fail to biosynthesize iron-sulphur clusters exhibit abnormalities in intracellular iron distribution and misregulated activation of high-affinity cellular iron uptake (Anderson et al. 2005; Kaplan and Kaplan 2009; Kim et al. 2001; Kispal et al. 1999; Lill and Muhlenhoff 2008). This connection has been unravelled in mammals, where the bifunctional protein ACO/IRP1 plays a central regulatory role in iron homeostasis by controlling RNA stability or mRNA translation of genes involved in iron metabolism. Formation and loss of the IRP1 [4Fe-4S] cluster regulates RNA binding and provides unique links between iron metabolism and cellular [Fe-S] cluster biogenesis (Anderson et al. 1823). In yeast, the association between $\mathrm{Fe}$ and $[\mathrm{Fe}-\mathrm{S}]$ metabolism has also been confirmed. Mitochondrial $[\mathrm{Fe}-\mathrm{S}]$ cluster biogenesis is required for both $\mathrm{Aft} 1 / \mathrm{Aft} 2$-dependent activation of the iron uptake response (among other actions against iron deficiency) and Yap5-dependent activation of high iron response genes (Li et al. 2012; Poor et al. 2014), providing a direct link between high and low iron sensing in $S$. cerevisiae via [Fe-S] clusters. Neither of these Fe regulatory mechanisms is conserved in plants (Arnaud et al. 2007). Nonetheless, as the $\mathrm{Fe}$ sensor in plants remains to be uncovered, and in light of the available evidence, the possibility of an [Fe-S]dependent $\mathrm{Fe}$-sensing mechanism in plants cannot be ruled out.

In this study, we characterized the phenotypes of A. thaliana plants overexpressing AtHSCB and $h s c b$ knockdown mutants showing altered iron homeostasis. The overexpression of AtHSCB led to activation of the iron uptake system and iron accumulation in roots without concomitant transport to shoots, resulting in reduced iron content in the aerial parts of plants. By contrast, $h s c b$ knockdown mutants presented the opposite phenotype, with iron accumulation in shoots despite the reduced levels of iron uptake in roots.
Taken together our data suggest that AtHSCB play a key role in iron metabolism, probably taking part in the control of iron translocation from roots to shoots.

\section{Materials and methods}

\section{Plant materials, molecular cloning and culture conditions}

Arabidopsis thaliana ecotype Col-0 was used in this study. Arabidopsis mutant lines SALK 099684 ( $h s c b 1)$ and SALK 020271 ( $h s c b 2$ ) were obtained from the Arabidopsis Biological Resource Center. T-DNA insertion lines were confirmed by PCR with T-DNA left border primer (LBal) and gene-specific primers (Up-hscb-prom and Rv-hscb-prom, see Table S1).

Arabidopsis plants overexpressing AtHSCB were obtained by cloning AtHSCB cDNA by PCR using Pfu polymerase (Promega, https://www.promega.com) and the primer pair AtHSCB-myc-fw/AtHSCB-myc-rv. The resulting PCR product was cloned into the pDonr221 vector by recombination (Gateway Technology, Invitrogen, http://www.invitrogen.com.ar). The $A t H S C B$ insert was transferred into the $\mathrm{pC}$-TAPa plasmid by recombination (Rubio et al. 2005) using the LR Clonase reaction to give rise to p-AtHSCB-myc. Arabidopsis was transformed with p-AtHSCB-myc by the floral dip method (Clough 1998). Gentamicin selected plants were confirmed by PCR with the primer pair HSCB-mycfwd/RtpCtaparv, and after three generations, homozygous lines were obtained.

For general plant growth, surface-sterilized seeds were plated on half-strength MS medium in Petri dishes. After stratification, the plants were grown under a $16 \mathrm{~h}$ light $/ 8 \mathrm{~h}$ dark cycle at $22^{\circ} \mathrm{C}$ in a growth chamber for 15 days. Three iron treatments were imposed: (a) Iron deficiency: halfstrength MS medium was prepared without iron, $20 \mu \mathrm{M}$ FeNaEDTA was added, and the plants were grown for 15 days; (b) Foliar iron: plants grown for 14 days on halfstrength MS medium were sprayed with $50 \mu \mathrm{M}$ Fe-EDTA as described previously (Garcia et al. 2013), and samples were taken after $24 \mathrm{~h}$; (c) $48 \mathrm{~h}$ iron depletion: plants grown for 13 days under standard conditions were transferred to iron depleted medium (half-strength MS medium prepared without iron plus BPS) for $48 \mathrm{~h}$ and then harvested. In the citrate treatment, plants grown for 13 days under standard conditions were transferred to either citrate supplemented medium (half-strength MS medium with the addition of $3 \mathrm{mM}$ sodium citrate) or fresh standard medium, and harvested after 2 days. 


\section{RNA extraction and quantitative real time PCR (qPCR)}

Three biological replicates, consisting each sample of leaves or roots pooled from 10 to 15 plants, were analyzed. Total RNA was extracted from rosette leaves and roots using the SV Total RNA Isolation System (Promega). Complementary DNA was synthesized using M-MLV reverse transcriptase (Promega) and random hexamers. The qPCR reactions were performed in a MiniOPTICON2 system (BioRad, http://www.bio-rad.com) using SYBR Green I (Invitrogen) as the detection reagent as previously described (Busi et al. 2011). Gene-specific primers for amplification of $150-250$ bp products were designed using primer3 software. Melt curve analysis were conducted to confirm the specificity of each assay. Gene expression levels were calculated using the comparative $\mathrm{Ct}$ method $\left(2^{-\Delta \Delta \mathrm{Ct}}\right)$ (Pfaffl 2001).

\section{Protein quantification and western blot}

Total protein concentrations were determined as described (Bradford 1976). SDS-PAGE was performed using 10\% P/V gels (Laemmli 1970). Protein bands were electro-blotted onto a nitrocellulose membrane (Bio-Rad), which was incubated with a-myc antibody (Santa Cruz, http://www. scbt.com). The antigen-antibody complex was visualized with alkaline phosphatase-linked a-mouse IgG, and BCIP and NBT staining (Bollag et al. 1996).

\section{Rosette area and lateral root length measurements}

Rosette area and lateral root (LR) length/number were assessed in 15-day-old seedlings by image analysis with Image J (http://imagej.nih.gov/ij/).

\section{Chlorophyll Assay}

Plants grown on half-strength MS medium for 15 days were harvested, and total chlorophyll was extracted from the shoots and assayed spectrophotometrically as previously described (Lichtenthaler 1987).

\section{Enzymatic activities}

Aconitase and succinate dehydrogenase activities were determined as previously reported (Busi et al. 2006) adding a desalting step of the protein extracts previous to each activity determination, measuring the formation of cis-aconitate at $240 \mathrm{~nm}$, and the oxidation of 2,6-dichlorophenolindophenol at $609 \mathrm{~nm}$, respectively. Malate dehydrogenase (MDH) activity was assayed spectrophotometrically in the oxaloacetate-reducing direction as described (Tripodi and Podestá 2003). All the activity determinations were performed in samples of pooled roots and shoots, at least in triplicate, and the mean values \pm standard deviation (SD) were reported.

Ferric-chelate reductase activity was monitored in whole intact root systems as described (Yuan et al. 2008). Five roots of 15-day-old seedlings, were rinsed with distilled pure water and submerged in assay solution $(200 \mu \mathrm{M}$ $\mathrm{CaSO}_{4}, 100 \mu \mathrm{M} \mathrm{Fe}(\mathrm{III}) \mathrm{NaEDTA}, 200 \mu \mathrm{M}$ phenantroline, $5 \mathrm{~mm}$ MES, pH 5.5). After $1 \mathrm{~h}$, an aliquot of the assay solution was removed and its absorbance was determined spectrophotometrically at $510 \mathrm{~nm}$. The Fe(II)-phenantroline concentration was calculated against a calibration curve of $\mathrm{Fe}\left(\mathrm{NH}_{4}\right)\left(\mathrm{SO}_{4}\right)_{2}$.

\section{Perls staining, in situ Perls/DAB intensification and iron quantification}

Iron stainings and quantification were performed on 15-dayold plants grown under iron sufficient conditions. Perls staining was performed as described in (Roschzttardtz et al. 2009), with minor modifications. Seedlings were washed three times with distilled water (5 min each wash), vacuum infiltrated with Perls stain solution $(4 \% \mathrm{HCl}, 4 \%$ potassium-ferrocyanide 1:1) for $5 \mathrm{~min}$. and left in the staining solution for 30 more min. at room temperature and in the dark. The stained samples were washed three times with distilled water and subjected to microscopic analysis [SMZ-2T microscopy connected to a TV Lens C- $0.45 \times$ (Nikon, http:// www.nikon.com)].

For histochemical iron localization, seedlings were fixed with ethanol/glacial acetic acid/formaldehyde (50/5/3.7\%) for $15 \mathrm{~h}$., washed with $0.01 \mathrm{M}$ phosphate buffer $(\mathrm{pH} 7.4)$ three times, and dehydrated in successive baths of 50,70, 90,96 , and $100 \%$ ethanol, $100 \%$ isopropanol, and $100 \%$ xylene. Then, the roots were embedded in paraffin, and thin Sections $(3 \mu \mathrm{m})$ were made. Finally, the sections were deposited on glass slides and stained with the Perls/DAB iron intensification protocol described in (Roschzttardtz et al. 2009).

For iron quantification, roots were separated from shoots and completely acid digested with $\mathrm{HNO}_{3}$. Total iron contents were measured spectrophotometrically with bathophenanthroline as indicated in Tarantino et al. (2010).

\section{Citrate quantification}

Citrate quantification was performed by gas chromatography mass spectrometry-based metabolite profiling. Extraction, liquid partition, and derivation prior to GC-MS analysis were performed as described by Lisec et al. (2006). For analysis, three biological replicates with a second group of technical replicates were utilized (six total data points). Citrate was unambiguously assigned using retention index and mass spectrum as the two most important identification 
criteria, and by running a standard of sodium citrate processed in the same way as the samples. Peak heights were normalized using the amount of the sample fresh weight and ribitol for internal standardization. Relative metabolite contents were informed.

\section{Results}

\section{Phenotypic characterization of $\boldsymbol{A}$. thaliana plants with modified levels of AtHSCB}

To analyze the physiological role of AtHSCB, we first identified and characterized two homozygous hscb knockdown mutant plants from the Salk Institute Genomic Analysis Laboratory database of sequenced T-DNA (hscbl: SALK_099684 and hscb2: SALK_020271), which carry single T-DNA insertions (Fig. S1a). Secondly, to strengthen our data, we generated transgenic plants overexpressing $A t H S C B$ under the control of the cauliflower mosaic virus $35 \mathrm{~S}$ promoter (Fig. S1b). Two independent homozygous overexpressing lines, designated $H S C B 1$ and $H S C B 2$, were selected in the T3 generation. We analyzed AtHSCB transcript levels in roots and leaves of 15-day-old seedlings grown on half-strength MS agar plates by quantitative realtime PCR (Fig. 1b). Compared with wild-type plants, AtH$S C B$ transcript levels in the $h s c b$ mutant lines were reduced by $40-50 \%$ in roots and $65-85 \%$ in shoots, whereas $A t H-$ $S C B$ transcript levels increased more than 10 - to 20 -fold in roots and one- to four-fold in leaves in $H S C B$-overexpressing lines. Western blot analysis using antibodies against the myc peptide confirmed the presence of recombinant AtHSCB-myc protein in $H S C B 1$ - and $H S C B 2$-overexpressing seedlings (Fig. 1c).

After 15 days of growth on half-strength MS agar plates, both overexpressing and knockdown mutant lines developed smaller seedlings than the wild-type line (Fig. 1a). Rosette area measurements confirmed the reduced seedling size (Fig. 1d), with an approximately $20 \%$ decrease in whole leaf area for all lines. In addition, the overexpressing and knockdown lines were chlorotic under this growing condition (Fig. 1a). Total chlorophyll quantification validated this observation: $h s c b 2$ had a $22 \%$ reduction in chlorophyll content, and the chlorophyll contents
(A)

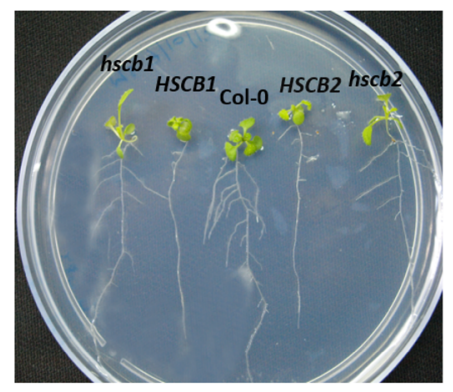

(B)

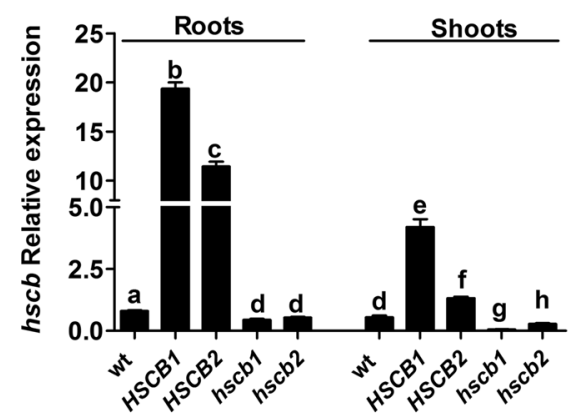

(C)

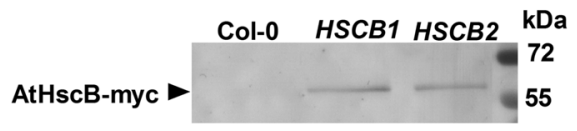

(D)

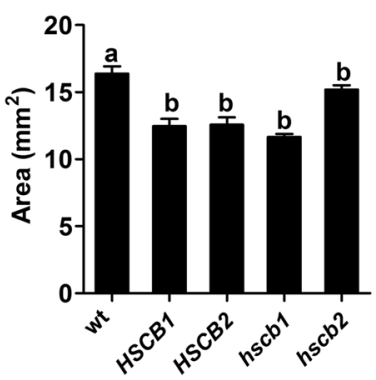

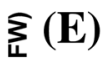

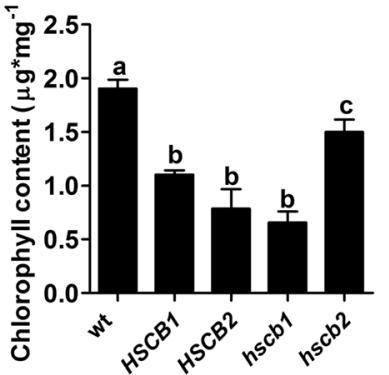

Fig. 1 Phenotypic characterization of $H S C B 1$, $H S C B 2$-overexpressing, $h s c b 1$ and $h s c b 2$ knockdown seedlings. a Phenotypic comparison of plants vertically grown on agar plates. b Quantitative real-time PCR analysis of AtHSCB transcript levels in seedlings of wild-type, hscb1, hscb2, HSCB1 and HSCB2 lines $(\mathrm{n}=3)$. Actin2 was used as an internal control. c Immunodetection of recombinant AtHSCB-myc protein expression in seedlings of wild-type, HSCB1 and HSCB2 lines

(F)

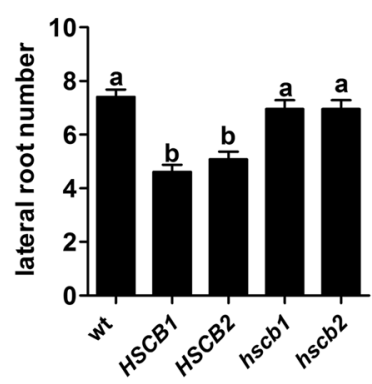

(G)

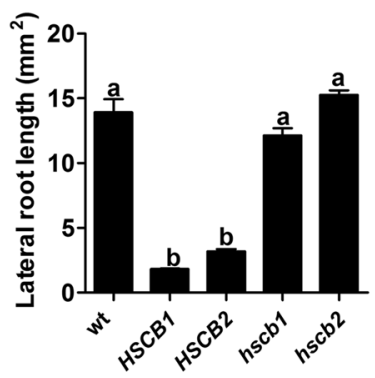

using a-myc peptide antibody. d Rosette area measurements, e total chlorophyll quantification, f LRt number, $\mathbf{g}$ LR length. Each analysis was performed on 15-day-old plants grown on half strength MS agar plates. 10-15 biological replicates were analyzed for each line. Bars with the same letter are not significantly different $(\mathrm{P}<0.05)$ by One Way Anova test 
in the other lines were less than half of wild-type levels (Fig. 1e). One of the most striking traits in the overexpressing plants was their root system architecture. Primary root growth in the mutant and overexpressing lines was not significantly different from that in wild-type seedlings. However, whereas the LR morphology of $h s c b$ seedlings was similar to that of wild type, the LR number (Fig. 1f) and LR length (Fig. 1g) of overexpressing lines were strongly reduced.

Arabidopsis AtHSCB T-DNA insertion mutants have reduced activities of the iron-sulphur enzymes ACO and $\mathrm{SDH}$, suggesting that AtHSCB plays a role in iron sulphur biogenesis in plants (Xu et al. 2009). To reassess the knockdown mutant plants and to survey the $[\mathrm{Fe}-\mathrm{S}]$ cluster assembly pathway in the overexpressing lines, we measured ACO and SDH activities in the leaves and roots of these lines. As a control, we measured the activity of $\mathrm{MDH}$, a tricarboxylic acid (TCA) cycle enzyme without [Fe-S] cofactors, to confirm that any difference in activity observed would be due to an alteration in [Fe-S] assembly and/or $[\mathrm{Fe}-\mathrm{S}]$ protein functions. Our results validate the previous findings, as in both roots and leaves of $h s c b$ lines, the activities of $[\mathrm{Fe}-\mathrm{S}]$ enzymes were reduced by more than $50 \%$ compared to wild type (Fig. 2a, b), while MDH activity remained unchanged (Fig. 2c). In the roots of HSCB (AtHSCB-overexpressing) lines, both ACO and SDH activities were higher than those of wild type (Fig. 2a, b). These results were not surprising, as these lines strongly overexpress a cochaperone of the $[\mathrm{Fe}-\mathrm{S}]$ biosynthetic pathway, but unexpectedly, ACO and SDH activities in $H S C B$ leaves were highly reduced relative to those of wild type. Since MDH activity was the same in each tissue and line, all differences observed in [Fe-S] enzymes activities appear to be due to a reduction in cofactor biosynthesis.

\section{AtHSCB affects total iron content, distribution and uptake}

Several lines of evidence point towards an alteration in iron metabolism as a possible cause for the phenotypes observed. First, since $\mathrm{Fe}$ is a substrate of [Fe-S] cluster biogenesis, it is feasible that low iron content or availability may lead to low cofactor assembly in the $H S C B$ lines. In other taxa such as fungi and metazoans, an intimate connection exists between $\mathrm{Fe}$ homeostasis and $[\mathrm{Fe}-\mathrm{S}]$ cluster biogenesis (Anderson et al. 1823; Lill et al. 2012). Furthermore, root system architecture is the combined result of genetically determined patterns and the environmental challenges to which plants are exposed, including nutrient accessibility, and iron availability can affect LR development (Giehl et al. 2012). Consequently, to establish the cause of the reduced ACO and SDH activity in $H S C B$ leaves, we analyzed the iron contents in all lines under investigation using various techniques.

First, we harvested 15-day-old seedlings grown under Fe sufficient condition and performed qualitative histochemical detection by Perls staining, revealing that $H S C B$ transgenic lines contained a significantly greater amount of ferric iron in their roots than wild-type and knockdown seedlings (Fig. 3a). Conversely, ferric iron levels in $h s c b$ roots were not significantly different from those of wild-type roots. However, upon closer inspection, iron tended to be concentrated outside the vascular bundle in the $H S C B$ lines, whereas in $h s c b$ lines, the metal appeared to be concentrated in vessels.

Second, to quantify total $\mathrm{Fe}$ content, we harvested and acid digested the plants and measured iron levels using a spectrophotometric technique. As shown in Fig. 3b, under Fe sufficient conditions, HSCB seedlings accumulated approximately fourfold more $\mathrm{Fe}$ in their roots than did the wild type. We did not detect any difference in Fe content
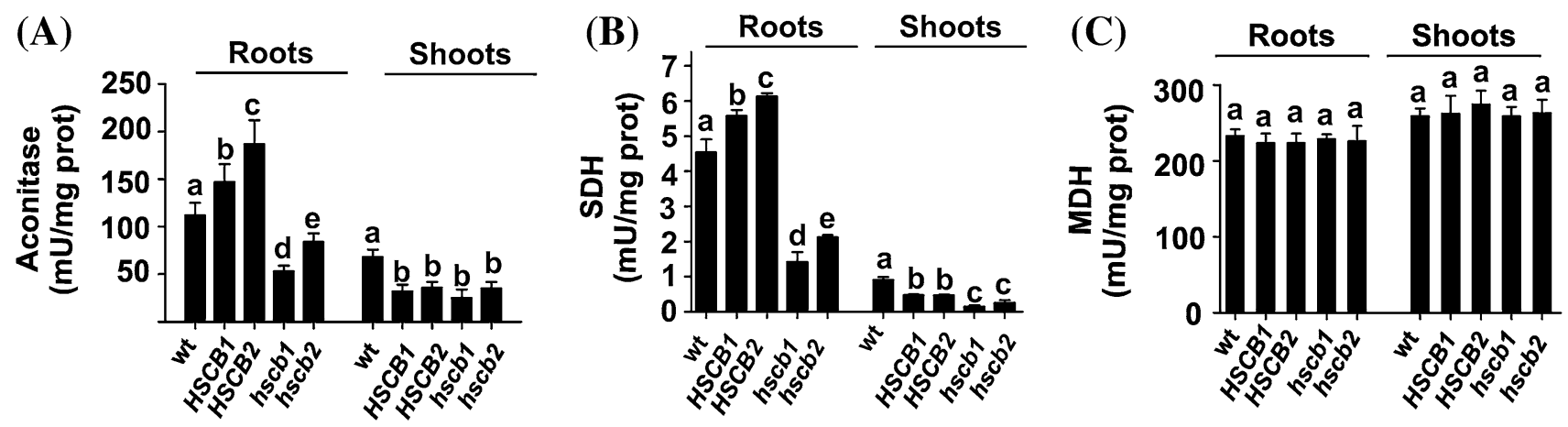

Fig. 2 The effect of AtHSCB on [Fe-S] enzymatic activity in roots and shoots. Plants were grown on half-strength MS agar medium for 15 days and harvested, and a ACO, b SDH, and c MDH activities were measured in pooled root and shoot tissues of wild-type, $H S C B$ and $h s c b$ lines. MDH, an enzyme lacking [Fe-S], was used as a control. Data are representative of means \pm SD from three independent experiments. Bars with the same letter are not significantly different $(\mathrm{P}<0.05)$ by One Way Anova test 
(A)

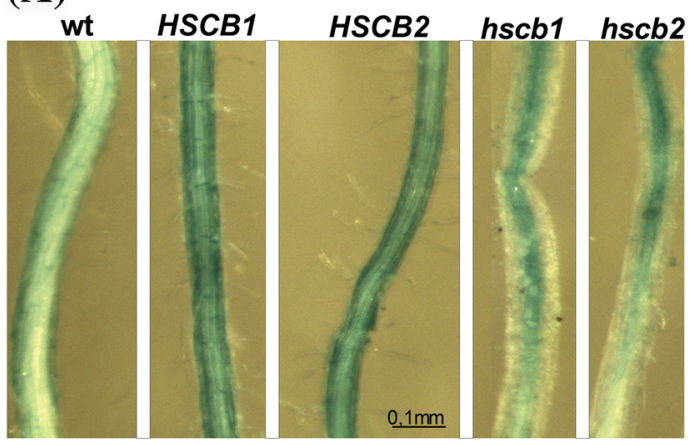

(B)

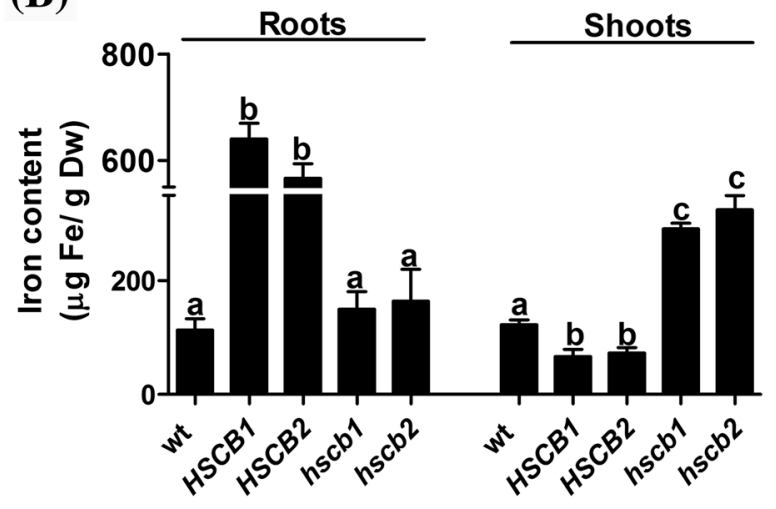

(C)

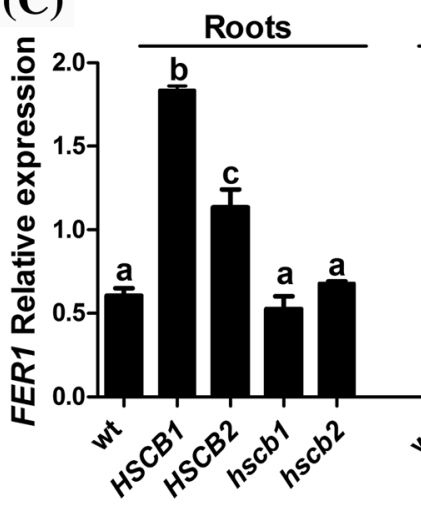

Fig. 3 Altered levels of AtHSCB affect iron partitioning between roots and shoots. Wild-type, $H S C B$ and $h s c b$ plants were grown on half-strength MS agar medium (iron sufficient conditions) for 15 days and harvested. a Histochemical Fe detection in roots by direct Perls staining. Bar represents $0.1 \mathrm{~mm}$. b Total Fe content in roots and shoots.

between wild-type and $h s c b$ plant roots. Conversely, Fe levels in knockdown line shoots were approximately twofold higher than in wild type, while the iron content in $H S C B$ shoots was nearly half that of wild-type shoots. These results clearly indicate that $\mathrm{Fe}$ distribution between (and probably within) roots and shoots in both the overexpressing and knockdown mutant lines was highly altered.

Finally, we analysed ferritin expression by qPCR to address the question of whether this anomalous iron content is localized inside or outside the cells in roots and shoots. A. thaliana has four ferritin genes, AtFER1-4 (Petit et al. 2001); AtFER1 is the most highly expressed ferritin gene in vegetative tissues (Reyt et al. 2015). Since AtFER1 is usually used as a marker of excess iron or free iron-induced cell oxidative stress (Ravet et al. 2009), measuring its transcript levels by qPCR provides an indirect way to measure symplastic iron levels. As shown in Fig. 3c, AtFER1 was highly expressed in $H S C B$ roots, indicating that the high levels of iron in these roots were primarily located inside the cells. However, although $h s c b$ leaves exhibited elevated iron levels, they also exhibited slightly reduced AtFERI expression.
Three biological replicate sets of pooled roots and shoots were subjected to iron analysis by a spectrophotometric technique. c Quantitative real time PCR analysis of AtFER1 transcript levels in roots and leaves $(\mathrm{n}=3)$. Actin2 was used as a control gene. Bars with the same letter are not significantly different $(\mathrm{P}<0.05)$ by One Way Anova test

This result might indicate that either (i) iron accumulated in the apoplastic space in leaves or (ii) that iron was present inside the cells but did not reach the chloroplasts, the organelle to which ferritins are mainly targeted [reviewed in Briat et al. (2010)]. Perls/DAB staining performed on 15-day-old plants grown on iron sufficient media seems to confirm both hypothesis (Fig. S2). hscb leaves displayed increased iron deposits around vascular tissues, pointing towards accumulation in the apoplastic space. Nevertheless, part of the leaf iron must be incorporated in mesophyll cells because some structures, probably the nucleus or nucleolus (Roschzttardtz et al. 2011), appeared deeply labeled. Wild-type and $H S C B$ leaves did not show these last iron dyed structures. The reduced FRO2 activity exhibited by $h s c b$ plants (see Fig. 4b) also suggests high availability of symplastic iron in leaves.

In an attempt to determine the mechanism by which overexpression and knockdown of $A t H S C B$ lead to abnormal iron content and distribution, we investigated the expression of FIT, FRO2, and IRT1; these genes are involved in root iron uptake and are commonly used as markers of 
Fig. 4 Iron uptake is elevated in $H S C B$ lines and reduced in $h s c b$ lines. Wild-type, $H S C B$ and $h s c b$ lines were grown on half-strength MS agar medium for 15 days. a Expression levels of FIT, IRT1 and FRO2. b Ferrochelate reductase activity. At least 20 roots were pooled and subjected to enzyme activity analysis $(\mathrm{n}=5)$. Bars with the same letter are not significantly different $(\mathrm{P}<0.05)$ by One Way Anova test
(A)

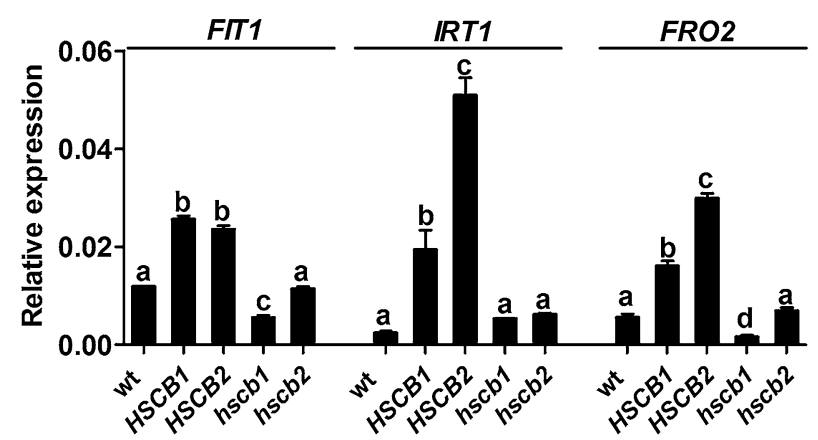

(B)

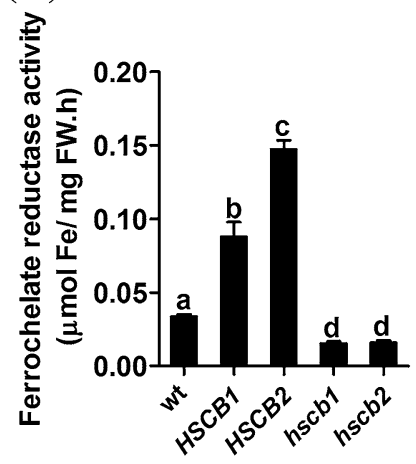

iron deficiency in Arabidopsis due to their rapid induction under this condition (Eide et al. 1996). When the seedlings were grown under iron sufficient conditions for 15 days, FIT transcript levels were approximately twofold higher in $H S C B$ lines than in wild-type plants. Conversely, hscb lines exhibited similar or lower levels of FIT transcripts than the wild type (Fig. 4a). Also, IRT1 and FRO2 transcript levels were high in $H S C B$-overexpressing lines, whereas in the knockdown lines, the transcript levels of these genes were not statistically different from those of wild-type plants. The only exception was $h s c b 1$, which exhibited reduced $F R O 2$ transcript levels. To establish whether the $\mathrm{FRO} 2$ transcript levels in $H S C B 1 / H S C B 2$ and $h s c b 1 / h s c b 2$ were correlated with protein abundance, we analyzed FRO2 activity. Consistent with its transcript accumulation, $\mathrm{FRO} 2$ activity was more than two- and three-fold higher in HSCB1 and HSCB2 roots, respectively, compared with wild-type roots. On the other hand, in the roots of hscb seedlings, FRO2 activity was one-half that of wild-type plants (Fig. 4b). These findings indicate that the iron uptake machinery of $H S C B$-overexpressing plants is constitutively activated when grown under iron sufficient conditions and that these plants behave like iron deficient plants. Conversely, knockdown mutant plants probably incorporate iron at a lower rate than the wild type because $\mathrm{Fe}(\mathrm{III})$ reduction is assumed to be the ratelimiting step in iron uptake (Connolly et al. 2003); these plants function as though they were growing under iron excess conditions.

\section{Correct functioning of the shoot-directed system controlling the iron deficiency response in roots}

Many studies suggest that the aerial parts of plants play an important role in regulating Fe deficiency responses (Enomoto et al. 2007; Lucena et al. 2006; Maas et al. 1988; Vert et al. 2003), particularly in the induction of key proteins in Strategy I iron uptake, such as FRO2 and IRT1. Nevertheless, it is not clear which pool of iron is sensed (apoplastic, cytoplasmic, vacuolar, mitochondrial, chloroplastic and so on), which molecular components are involved in the sensing mechanism and how the response is transduced to the root. The proper functioning of the shoot-directed system controlling root Fe deficiency responses is usually verified by foliar application of iron to Fe-deficient plants; when this system functions correctly, a strong decrease in FRO2 activity is observed (Garcia et al. 2013).

The altered gene transcript levels of the major elements in the root iron uptake system and FRO2 enzymatic activity are in accordance with the abnormal leaf iron contents detected in the lines under investigation. We next examined whether AtHSCB interferes with signal transduction when leaf iron contents are altered. We sprayed the leaves of $H S C B$-overexpressing and mutant lines with Fe-EDTA and measured FRO2, ACO, SDH and MDH activity $24 \mathrm{~h}$ later. After the Fe-EDTA treatment, FRO2 activity did not change significantly in $h s c b$ and wild-type roots, whereas it decreased approximately $50 \%$ in $H S C B$ roots compared to the respective controls (Fig. 5a). Leaf SDH and MDH activity did not change in either line in response to Fe-EDTA treatment, nor did ACO activity in $h s c b$ and wild-type leaves. However, ACO activity increased more than $50 \%$ in $H S C B 1$-overexpressing leaves, compared to their control conditions (Fig. 5b). These and the above results indicate that the aerial part of the plants control iron uptake in roots. FRO2 activity was high in $H S C B$-overexpressing plants due to the low iron content in leaves, and it was low in knockdown mutant roots due to the high levels of iron in leaves (Fig. 3b). Moreover, when the leaf iron content increased in $H S C B$-overexpressing seedlings due to spray application of Fe-EDTA, FRO2 activity decreased, demonstrating that the foliar iron sensing mechanism functions correctly, as does the response system controlled by the aerial part of the plant. In addition, ACO activity increased when $\mathrm{Fe}$ was sprayed onto $H S C B$ leaves, indicating that the low ACO activity in the shoots of these lines is due to the low leaf iron content, which probably limits [Fe-S] cluster assembly.

The mechanism that controls iron uptake in plants has been well studied. However, little is known about how iron is transported from roots to shoots and how this process is regulated. To shed some light on this issue, we measured 
(A)

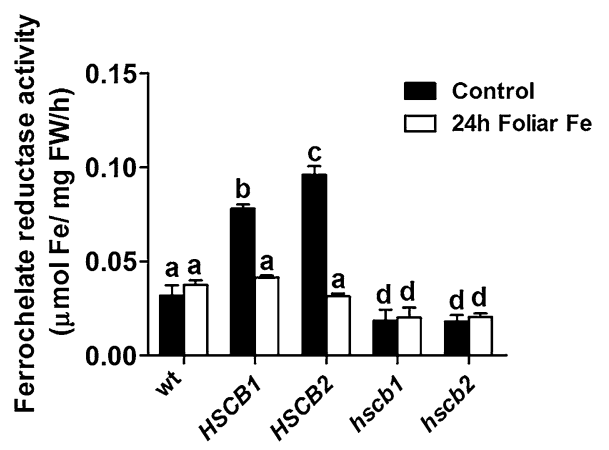

(B)

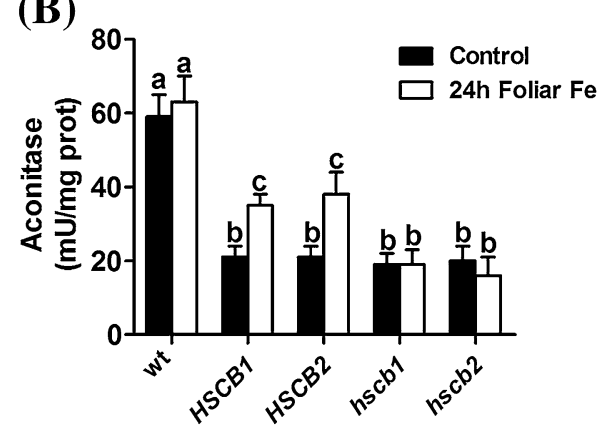

Fig. 5 The shoot-directed control of iron deficiency responses in roots functions properly. Leaves of plants grown for 14 days under ironsufficient conditions were sprayed with $50 \mu \mathrm{M}$ Fe-EDTA or water (control). a Ferrochelate reductase activity in pooled roots $(n=5)$ and

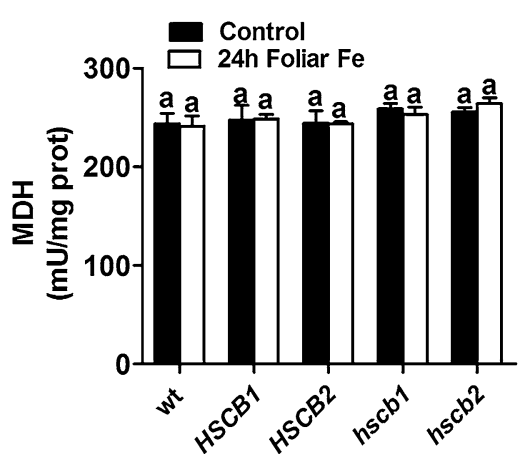

b ACO, SDH and MDH activities in pooled shoots $(\mathrm{n}=3)$ at $24 \mathrm{~h}$ after treatment. Bars with the same letter are not significantly different $(\mathrm{P}<0.05)$ by Two Way Anova test

Romheld 2003; Rodriguez-Lucena et al. 2009; Roosta and ohsenian 2012). Moreover, hscb FRO2 activity increased after citrate treatment in agreement with the reduced leaf iron content (Fig. 6c). These results confirm once again that the leaf homeostatic mechanism controlling iron uptake is working properly.

\section{Which other iron homeostatic mechanism is affected in plants with altered AtHSCB levels?}

A clue about a possible way in which anomalous iron distribution is alleviated came from observation of the lines under iron-deficient conditions. The foliar areas of overexpressing and knockdown mutant lines grown under Fe-deficient conditions $(20 \mu \mathrm{M} \mathrm{Fe})$ for 15 days were 50 and $30 \%$ larger, respectively, than those of wt lines, indicating that $H S C B$ and $h s c b$ lines grew better under these conditions than wild type (Fig. 6). We therefore reasoned that the absence of iron might unlock ( $H S C B$ lines) or normalize ( $h s c b$ lines) iron transport.

To investigate this notion, we studied Fe contents in roots and leaves of $H S C B$ and $h s c b$ plants that were grown for 13 days under iron sufficiency and transferred to medium devoid of iron. After $48 \mathrm{~h}$ of iron absence, all lines exhibited a general decrease in root iron levels, but consistent 
(A) citrate
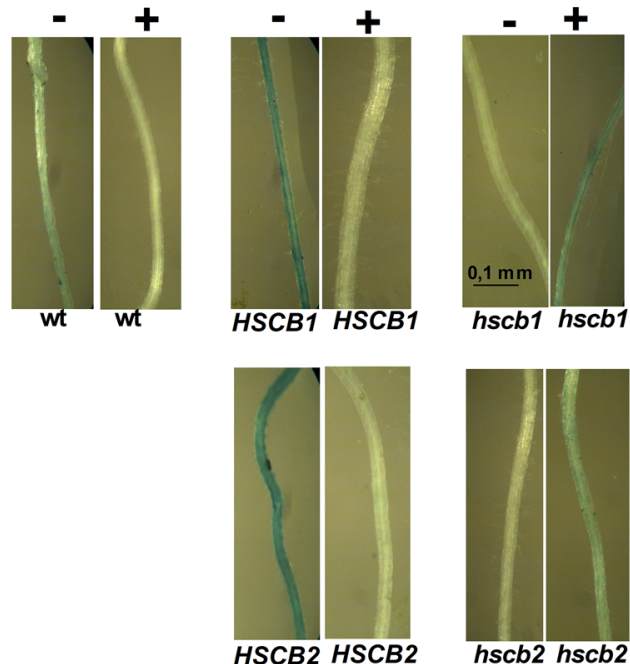

(C)

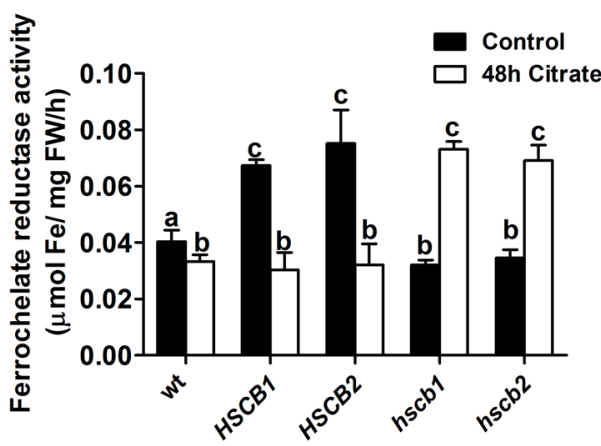

Fig. 6 Citrate supplementation modifies iron distribution in roots and shoots. Plants grown for 13 days under iron-sufficient conditions were transferred to half-strength MS medium supplemented with $3 \mathrm{mM}$ sodium citrate or fresh half-strength MS agar medium for $48 \mathrm{~h}$. a Histochemical $\mathrm{Fe}$ detection in roots by direct Perls staining. Bar represents $0.1 \mathrm{~mm}$. b Total Fe content in shoots. Three biological replicate

with our hypothesis, this decrease was more pronounced in overexpressing lines: between $30-40 \%$ in wt, $h s c b l$ and hscb2 vs. $50-60 \%$ in $H S C B 1$ and $H S C B 2$ lines, respectively. Moreover, wt and $h s c b$ lines exhibited reductions in iron levels in leaves of approximately $50 \%$ compared to the controls, whereas these levels increased 40 and $50 \%$ in $H S C B 1$ and HSCB2 leaves, respectively (Fig. 7a). The results suggest that the shoot-directed control of iron uptake by the root continues operating properly, as FRO2 activity increased 3.7-fold in wild-type roots and twofold in $h s c b$ roots (reduced leaf iron content), whereas in $H S C B$ roots, FRO2 activity decreased $50 \%$ (increased leaf iron content; Fig. 7b). These results confirm the notion that in the absence of $\mathrm{Fe}$, the knockdown lines accumulated lower levels of leaf iron (as expected) and, more importantly, the overexpressing lines were able to transport the iron trapped in their roots to the shoots. Taken together, these results indicate that the decrease in root iron levels, or some signal or metabolic
(B)

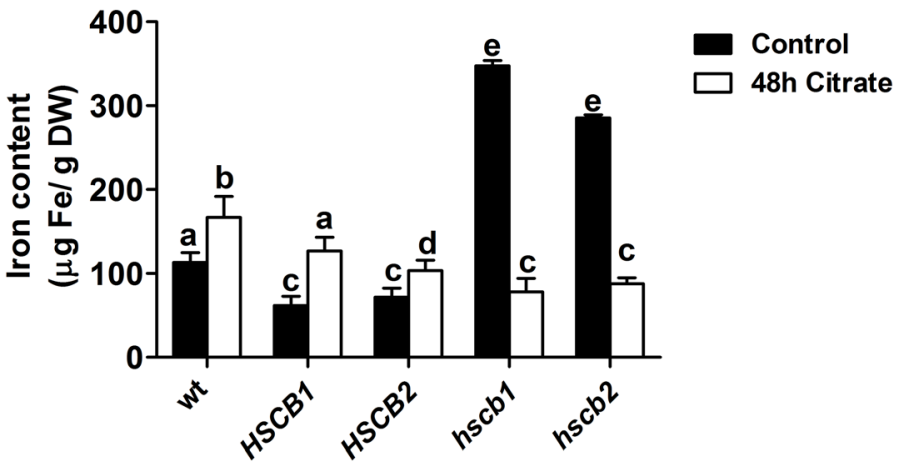

(D)

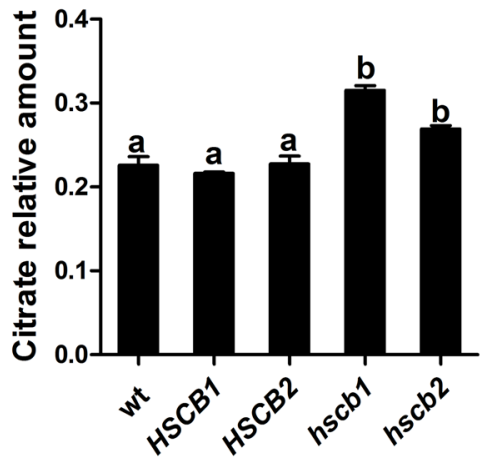

sets of pooled shoots were subjected to iron analysis by a spectrophotometric technique. $\mathbf{c}$ Ferrochelate reductase activity in pooled roots $(n=5)$. d Relative abundance of citrate in roots of 15-day-old plants grown on iron sufficient conditions (half strength MS medium). Bars with the same letter are not significantly different $(\mathrm{P}<0.05)$ by One Way Anova test

consequence derived from this decrease, unlocks iron transport from root-to-shoot in $H S C B$-overexpressing plants.

\section{Discussion}

\section{AtHSCB is involved in [Fe-S] biosynthesis and affects iron metabolism}

To date, few studies have investigated the biological function of AtHSCB and its participation in the formation of [Fe-S] clusters (Leaden et al. 2014; Xu et al. 2009). In the current study, we examined the role of this protein in vivo, making use of plants with gain- and loss-of-function of AtHSCB. The activities of the [Fe-S] enzymes ACO and SDH were markedly reduced in the knockdown lines, whereas these enzyme activities increased in the roots of the overexpressing lines. On the contrary, the activity of 
(A)

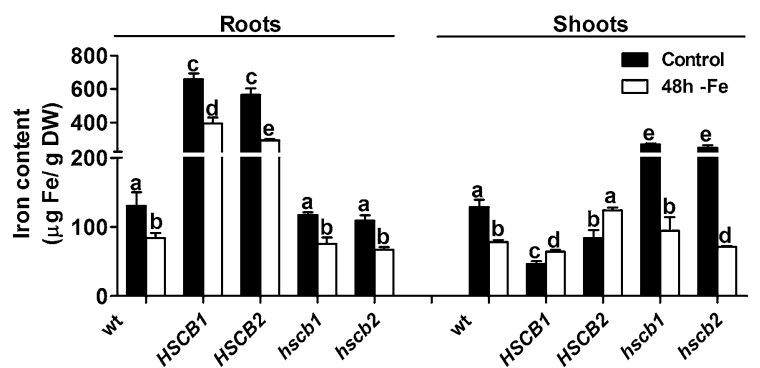

(B)

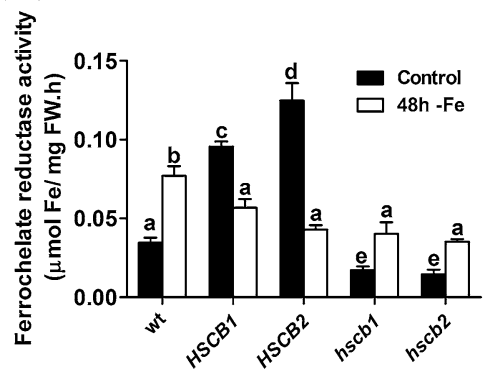

Fig. 7 Iron deficiency restores Fe transport from roots to shoots in $h s c b$ and $H S C B$ plants. Plants grown for 13 days under iron-sufficient conditions were transferred to iron-deficient (no added $\mathrm{Fe}$ ) or fresh half-strength MS agar medium for $48 \mathrm{~h}$. a Total $\mathrm{Fe}$ contents in roots and shoots were determined in three biological replicate sets of pooled tissues. b Ferrochelate reductase activity in pooled roots $(n=5)$. Bars with the same letter are not significantly different $(\mathrm{P}<0.05)$ by Two Way Anova test the Krebs cycle enzyme MDH, which is devoid of [Fe-S], was unaffected in both lines, demonstrating that only ironsulphur enzyme activities were altered (Fig. 2). Thus, our results clearly show that modifications in the expression of the cochaperone AtHSCB alter [Fe-S] cluster biogenesis, confirming its role in this plant biosynthetic pathway.

In addition, the hscb lines were chlorotic and grew slowly, both of which are common features of plants with deficient [Fe-S] biosynthesis [atm3 (Kushnir et al. 2001), isul, nfs1 (Frazzon et al. 2007), atfh1 (Busi et al. 2006)]. While the reasons for the chlorosis are somewhat difficult to unravel, and only atm 3 lines have been investigated in some detail (Bernard et al. 2009), the slow growth phenotype might be explained by the impact of low ACO and SDH activity on TCA cycle flux (Balk and Schaedler 2014). $H S C B$ plants were also chlorotic and smaller than wild-type lines. Nevertheless, the ultimate cause of both phenotypic traits is the low leaf iron content in these plants. Low iron availability affects chlorophyll biosynthesis (Msilini et al. 2013) and likely iron-sulphur biogenesis, which in turn reduces the activity of $\mathrm{ACO}$ and $\mathrm{SDH}$, among other [Fe-S] enzymes, with similar effects on Krebs cycle flux to that of $h s c b$ plants. This finding was clearly confirmed in the current study: when leaf iron contents increased in $H S C B$ plants due to foliar application or by reduced or no iron in the medium, $[\mathrm{Fe}-\mathrm{S}]$ enzyme activities recovered (Fig. $5 \mathrm{~b}$ ) and the plants grew better (Fig. S4).

Another unusual characteristic of the $H S C B$-overexpressing plants was their root architecture system (Fig. 1a, $\mathrm{f}, \mathrm{g}$ ). Root system architecture is the combined result of a genetically determined pattern and the environmental challenges to which plants are exposed, including limited nutrient availability. Morphological changes in the LR system in response to varying $\mathrm{Fe}$ availability in the media have been reported (Giehl et al. 2012). LR length increases in a dose-response manner up to conditions of iron sufficiency (approximately $25-50 \mu \mathrm{M} \mathrm{Fe}$ ), allowing the plant to explore different niches. At these Fe concentrations, the dose response is reversed and LR length decreases (Giehl et al. 2012), probably to prevent excessive iron uptake. LR number and density are also altered by inner iron availability, although less drastically. These changes are triggered by locally accumulated $\mathrm{Fe}$ in the root tissue, which is thought to be integrated into a sensing mechanism to adjust LR system architecture (Giehl et al. 2012). These observations may explain the root architecture of $H S C B$ : the high iron content in these roots may reduce LR initiation (number or density) and severely inhibit LR extension. On the contrary, $h s c b$ seedlings exhibit typical root system architecture because their root iron content is normal.

\section{Regulation of iron metabolism: shoot-directed control of root iron deficiency responses}

In vascular plants, communication between different plant organs is necessary to avoid imbalances in the nutrient supply and to integrate the nutritional demands of the whole plant (Schmidt 2003). Most studies suggest that the aerial part of the plant plays a key role in regulating Fe deficiency responses (Enomoto et al. 2007; Lucena et al. 2006; Maas et al. 1988; Vert et al. 2003), and these signals appear to be predominant over root iron responses (Enomoto et al. 2007; Garcia-Mina et al. 2013). A model has been proposed describing how both promotive and repressive signals (Vert et al. 2003), sent from shoots to roots in response to foliar iron status or to some related metabolite, regulate Fe deficiency responses, most likely through the phloem (Curie and Briat 2003; Lucena et al. 2006; Maas et al. 1988). In light of this model, to help elucidate the reason for the imbalanced Fe distribution in $H S C B$ and $h s c b$ seedlings, we investigated the main iron uptake system. $H S C B$ plants, containing low levels of foliar iron, exhibited high activation of the iron uptake system, with increased transcript levels of FIT1, $F R O 2$ and IRT1 and increased FRO2 activity, whereas $h s c b$ plants, with high shoot iron contents, exhibited reduced FRO2 activity (Fig. 4). Thus, our results are consistent with 
the model describing how the aerial part of the plant regulates Fe uptake in roots (Vert et al. 2003).

Changes in foliar iron availability induce the biosynthesis and/or transport of a signalling molecule that conveys this information to the root via the phloem (Schmidt 2003). Previous studies have demonstrated that foliar application of iron to Fe-deficient wild-type Arabidopsis, pea and tomato plants drastically reduces FRO2 activity (Enomoto et al. 2007; Garcia et al. 2013; Maas et al. 1988). To investigate whether shoot-to-root signalling takes place in the $H S C B$ lines to deactivate FRO2, we performed foliar treatment of $H S C B$ and $h s c b$ lines grown under Fe sufficient condition with Fe-EDTA. After 24 h, FRO2 activity was reduced in the $H S C B$ lines (Fig. 5), indicating that in these plants, the iron sensing and signalling mechanisms function correctly, and signals coming from shoots are properly sent to roots.

The foliar regulatory system presumably involves two unknown sensors: one for sensing the nutrient status of the shoot and one in the root that perceives the long-distance signals coming from the shoot (Schmidt 2003). The results of the foliar iron treatment experiment indicate that in $H S C B$ plants, these two sensors function properly. Moreover, the results of the citrate supplementation assay (Fig. 6) and the iron deficiency treatment experiment (Fig. 7) reinforce this conclusion and extend it to hscb seedlings. In both $H S C B$ and $h s c b$ lines, after $48 \mathrm{~h}$ of citrate supplementation or iron deficiency, FRO2 activity changed in accordance with the resulting variations in foliar iron levels: $H S C B$ plants (with increased foliar iron levels) exhibited reduced FRO2 activity, whereas $h s c b$ seedlings (with reduced shoot iron content) exhibited increased FRO2 activity. This last result also imply that [Fe-S] clusters are not involved in these two sensing mechanisms, as the hscb lines, which are deficient in $[\mathrm{Fe}-\mathrm{S}]$ biogenesis, responded to changes in shoot iron levels as expected. Moreover, [Fe-S] clusters are neither the sensed nutrient signal in the shoot nor implicated in the signal sent to the root.

\section{Iron redistribution: effect of citrate treatment}

In general, our results are consistent with an alteration in iron transport between roots and shoots. $H S C B$ plants actively incorporate iron from the medium (Fig. 4), and although genes related to $\mathrm{Fe}$ transport and redistribution, such as FRD3, FPN1 and NAS4, are induced (Fig. S3), iron is trapped in roots and not delivered to leaves, which are Fe deficient (Fig. 3). By contrast, in hscb seedlings, iron uptake is reduced and FPN1 is repressed, but iron accumulates in leaves. Little is known about $\mathrm{Fe}$ transport from roots to shoots, and many questions remain. Nonetheless, studies of the Arabidopsis frd 3 mutant have provided molecular evidence for the role of citrate in long-distance Fe transport (Durrett et al. 2007; Green and Rogers 2004; Rogers and Guerinot 2002). Iron is thought to be transported in the xylem as different complexes with citrate and malate (Flis et al. 2016; Grillet et al. 2014), because free Fe ionic forms can be toxic and are also prone to precipitation at the neutral or slightly acidic $\mathrm{pH}$ values typical of xylem sap (Abadia et al. 2011). The TCA cycle provides abundant organic acids, including citrate and malate (Lopez-Millan et al. 2000). The TCA cycle possesses two Fe-containing enzymes, ACO and $\mathrm{SDH}$, and under Fe deficiency, it can shift from circular to linear mode (Steuer et al. 2007) due to the reduced activity of both enzymes (Vigani 2012). In these situations, increased citrate export from the mitochondria to the cytosol has been observed in several plant species (Vigani et al. 2009), which may enhance $\mathrm{Fe}$ transport from roots to shoots.

ACO and SDH activity were considerably reduced in the $h s c b$ lines (Fig. 2), and indeed root citrate content was higher than in wild type line (Fig. 6d). Nevertheless elevated citrate levels were probably not the cause of the high iron contents in their shoots. Citrate supplementation assay, which is expected to increase citrate content even more, switched iron distribution in these plants instead of reinforcing the phenotype (Fig. $6 \mathrm{a}, \mathrm{b}$ ). Conversely, the increase in ACO and SDH activity observed in $H S C B$ roots suggests that this alteration in the TCA cycle could lead to imbalanced organic acid content. It would be conceivably to assume a decline in citrate levels as the cause of the decreased iron transport from roots to shoots. Moreover, in light of the results from the citrate supplementation assay, this notion would be reinforced. However, altered citrate levels were presumably not responsible for the phenotype since $H S C B$ and Col 0 plants showed the same root citrate content in iron sufficient conditions (Fig. 6d).

\section{Regulation of iron metabolism: checkpoint at the root- to-shoot translocation level}

It has become evident that shoot-directed control of root iron deficiency responses is not the only iron homeostatic mechanism in plants (Schmidt and Buckhout 2011). A number of transcription factors and other regulatory proteins, such as PYE, HRZs/BTS, bHLH100 and bHLH101, are controlled by iron starvation, many of which appear not to be regulated by FIT, demonstrating the existence of additional regulatory networks driving responses to low iron (Long et al. 2010; Sivitz et al. 2012). Cell-type-specific transcriptional profiling has revealed that the stele is the most responsive cell type to iron deprivation within the root and that many genes induced under these conditions encode transcription factors (Dinneny et al. 2008). Therefore, the vascular bundle may serve as a transcriptional regulatory centre for the iron deficiency response (Long et al. 2010). On the other hand, elevated iron contents can become extremely toxic, causing symptoms such as brown and necrotic degenerative leaves 
(Lucena et al. 2015). It has been observed that leaf iron levels are not affected by $48 \mathrm{~h}$ and 1 week of excess Fe treatment in Arabidopsis (Reyt et al. 2015) and rice (Liang et al. 2014), respectively, indicating that Fe in these plants is not transported from root to shoot. These findings suggest that different pathways exist for inter-organ regulation of the responses to iron excess, and that a checkpoint operating at the root-to-shoot translocation level may exist (Reyt et al. 2015). However, unlike animals, fungi and bacteria, in which ionic $\mathrm{Fe}$ or $[\mathrm{Fe}-\mathrm{S}]$ clusters are the main elements sensed in iron metabolism (Anderson et al. 1823; Lee and Helmann 2007; Poor et al. 2014), our understanding of iron sensors in plants remains limited, and it is not clear which signals regulate these homeostatic pathways.

Our results show that $H S C B$ lines have reduced Fe contents in shoots, whereas hscb lines have increased Fe contents in shoots, suggesting that $\mathrm{Fe}$ transport from roots to shoots in these lines is altered. We also observed that under iron deficient conditions both $H S C B$ and $h s c b$ plants grew better than Col 0 plants (Fig. S4) and we reasoned that iron levels might affect a checkpoint controlling iron translocation to shoots. BTS, a known iron sensor and regulatory protein highly expressed in vascular tissues, whose stability is controlled by iron binding to its hemerythrin domains (Selote et al. 2015), also possesses a rubredoxin domain. AtHSCB contains such a domain as well, which is conserved in all higher eukaryotes but not in yeast or bacteria (Bitto et al. 2008). The rubredoxin-type fold binds metal ions including $\mathrm{Fe}$ and $\mathrm{Zn}$, as well as $[\mathrm{Fe}-\mathrm{S}]$ clusters (Sieker et al. 1986) and it is probably responsible for the stability of HSC20, the AtHSCB human homolog. Mutant HSC20, in which the four conserved cysteines of the rubredoxin domain were replaced by serines showed a clearly lower abundance than the native protein upon transient expression in HeLa cells (Uhrigshardt et al. 2010). However, little is known about the role of this domain beyond its involvement in various functions distantly related to iron metabolism, such as redox processes (Hagelueken et al. 2007) and accumulation of photosystem II in oxygenic phototrophs (Calderon et al. 2013). It might be hypothesized that upon iron binding AtHSCB would be stabilized, and would control iron translocation from root to shoot. High iron levels -or high AtHSCB levels, as in the overexpressor lines- might reduce iron transport to the shoot. We observed that after $48 \mathrm{~h}$ of iron deficiency, the shoot Fe content decreased in wild-type and $h s c b$ plants and increased in $H S C B$ seedlings; thus, the iron trapped in $H S C B$ roots could be transported to the shoots (Fig. 7). This finding supports the idea that a checkpoint of iron transport might operate in Arabidopsis roots. Under iron deficiency, AtHSCB would be destabilized, and transport from roots to shoots would increase to satisfy metabolic needs in the shoot. Conversely, under Fe excess, transport from root to shoot would be inhibited, in an AtHSCB dependent mechanism, to avoid shoot toxicity. Indeed, it has been observed that after iron excess treatment $H S C B$ transcripts are induced in rice roots (Liang et al. 2014). This AtHSCB regulatory mechanism might be performed in the cytosol, where small amounts of AtHSCB and HSC20 have been detected (Uhrigshardt et al. 2010; Xu et al. 2009).

In summary, our results provide new evidence supporting the involvement of AtHSCB, a protein from the [Fe-S] cluster mitochondrial biosynthetic pathway, in iron translocation from roots to shoots.

Acknowledgments This work was supported by grants from Agencia Nacional de Promoción Científica y Técnológica (ANPCyT PICT 2013-2188 and 2014-2184). MB is a Doctoral fellow from ANPCyT. MAP, MVB and DGC are research members from CONICET.

Author contributions LL, MAP, MB performed the required experiments and analyzed the data. MAP, MVB and DFGC designed the conception and delineation of the study, wrote the manuscript and reviewed it before submission. All authors read and approved the final manuscript.

\section{References}

Abadia J, Vazquez S, Rellan-Alvarez R, El-Jendoubi H, Abadia A, Alvarez-Fernandez A, Lopez-Millan AF (2011) Towards a knowledge-based correction of iron chlorosis. Plant Physiol Biochem 49:471-482

Anderson CP, Shen M, Eisenstein RS, Leibold EA (2012) Mammalian iron metabolism and its control by iron regulatory proteins. Biochim Biophys Acta 1823:1468-1483

Anderson PR, Kirby K, Hilliker AJ, Phillips JP (2005) RNAi-mediated suppression of the mitochondrial iron chaperone, frataxin, in Drosophila. Hum Mol Genet 14:3397-3405

Arnaud N, Ravet K, Borlotti A, Touraine B, Boucherez J, Fizames C, Briat JF, Cellier F, Gaymard F (2007) The iron-responsive element (IRE)/iron-regulatory protein 1 (IRP1)-cytosolic aconitase iron-regulatory switch does not operate in plants. Biochem $\mathrm{J}$ 405:523-531

Balk J, Lobreaux S (2005) Biogenesis of iron-sulfur proteins in plants. Trends Plant Sci 10:324-331

Balk J, Pilon M (2011) Ancient and essential: the assembly of ironsulfur clusters in plants. Trends Plant Sci 16:218-226

Balk J, Schaedler TA (2014) Iron cofactor assembly in plants. Annu Rev Plant Biol 65:125-153

Barberon M, Zelazny E, Robert S, Conejero G, Curie C, Friml J, Vert G (2011) Monoubiquitin-dependent endocytosis of the ironregulated transporter 1 (IRT1) transporter controls iron uptake in plants. Proc Natl Acad Sci USA 108:E450-E458

Beinert H (2000) Iron-sulfur proteins: ancient structures, still full of surprises. J Biol Inorg Chem 5:2-15

Bernard DG, Cheng Y, Zhao Y, Balk J (2009) An allelic mutant series of ATM3 reveals its key role in the biogenesis of cytosolic ironsulfur proteins in Arabidopsis. Plant Physiol 151:590-602

Bitto E, Bingman CA, Bittova L, Kondrashov DA, Bannen RM, Fox BG, Markley JL, Phillips GN Jr (2008) Structure of human J-type co-chaperone $\mathrm{HscB}$ reveals a tetracysteine metal-binding domain. J Biol Chem 283:30184-30192

Bollag DM, Rozycki MD, Edelstein SJ (1996) Protein methods. Wiley-Liss, New York 
Bonomi F, Iametti S, Morleo A, Ta D, Vickery LE (2008) Studies on the mechanism of catalysis of iron-sulfur cluster transfer from IscU[2Fe2S] by $\mathrm{HscA} / \mathrm{HscB}$ chaperones. BioChemistry 47:12795-12801

Bradford MM (1976) A rapid and sensitive method for the quantitation of microgram quantities of protein utilizing the principle of protein-dye binding. Anal Biochem 72:248-254

Briat JF, Duc C, Ravet K, Gaymard F (2010) Ferritins and iron storage in plants. Biochim Biophys Acta 1800:806 -814

Busi MV, Gomez-Casati DF (2012) Exploring frataxin function. IUBMB Life 64:56-63

Busi MV, Gomez-Lobato ME, Rius SP, Turowski VR, Casati P, Zabaleta EJ, Gomez-Casati DF, Araya A (2011) Effect of mitochondrial dysfunction on carbon metabolism and gene expression in flower tissues of Arabidopsis thaliana. Mol Plant 4:127-143

Busi MV, Maliandi MV, Valdez H, Clemente M, Zabaleta EJ, Araya A, Gomez-Casati DF (2006) Deficiency of Arabidopsis thaliana frataxin alters activity of mitochondrial $\mathrm{Fe}-\mathrm{S}$ proteins and induces oxidative stress. Plant J 48:873-882

Busi MV, Zabaleta EJ, Araya A, Gomez-Casati DF (2004) Functional and molecular characterization of the frataxin homolog from Arabidopsis thaliana. FEBS Lett 576:141-144

Calderon RH, Garcia-Cerdan JG, Malnoe A, Cook R, Russell JJ, Gaw C, Dent RM, de Vitry C, Niyogi KK (2013) A conserved rubredoxin is necessary for photosystem II accumulation in diverse oxygenic photoautotrophs. J Biol Chem 288:26688-26696

Carrasco-Gil S, Rios JJ, Álvarez-Fernández A, Abadía A, García-Mina JM, Abadía J (2016) Effects of individual and combined metal foliar fertilization on iron- and manganese-deficient Solanum lycopersicum plants. Plant Soil 402:27-45

Clough SJ, Bent AF (1998) Floral dip: a simplified method for Agrobacterium-mediated transformation of Arabidopsis thaliana. Plant J 16:735-743

Colangelo EP, Guerinot ML (2004) The essential basic helix-loophelix protein FIT1 is required for the iron deficiency response. Plant Cell 16:3400-3412

Connolly EL, Campbell NH, Grotz N, Prichard CL, Guerinot ML (2003) Overexpression of the FRO2 ferric chelate reductase confers tolerance to growth on low iron and uncovers posttranscriptional control. Plant Physiol 133:1102-1110

Cupp-Vickery JR, Peterson JC, Ta DT, Vickery LE (2004) Crystal structure of the molecular chaperone HscA substrate binding domain complexed with the IscU recognition peptide ELPPVKIHC. J Mol Biol 342:1265-1278

Curie C, Briat JF (2003) Iron transport and signaling in plants. Annu Rev Plant Biol 54:183-206

Darbani B, Briat JF, Holm PB, Husted S, Noeparvar S, Borg S (2013) Dissecting plant iron homeostasis under short and long-term iron fluctuations. Biotechnol Adv 31:1292-1307

Dinneny JR, Long TA, Wang JY, Jung JW, Mace D, Pointer S, Barron C, Brady SM, Schiefelbein J, Benfey PN (2008) Cell identity mediates the response of Arabidopsis roots to abiotic stress. Science 320:942-945

Durrett TP, Gassmann W, Rogers EE (2007) The FRD3-mediated efflux of citrate into the root vasculature is necessary for efficient iron translocation. Plant Physiol 144:197-205

Dutkiewicz R, Schilke B, Cheng S, Knieszner H, Craig EA, Marszalek J (2004) Sequence-specific interaction between mitochondrial Fe-S scaffold protein Isu and Hsp70 Ssq1 is essential for their in vivo function. J Biol Chem 279:29167-29174

Eide D, Broderius M, Fett J, Guerinot ML (1996) A novel iron-regulated metal transporter from plants identified by functional expression in yeast. Proc Natl Acad Sci USA 93:5624-5628

Enomoto Y, Hodoshima H, Shimada H, Shoji K, Yoshihara T, Goto F (2007) Long-distance signals positively regulate the expression of iron uptake genes in tobacco roots. Planta 227:81-89
Flis P, Ouerdane L, Grillet L, Curie C, Mari S, Lobinski R (2016) Inventory of metal complexes circulating in plant fluids: a reliable method based on HPLC coupled with dual elemental and high-resolution molecular mass spectrometric detection. New Phytol 211:1129-1141

Fourcroy P, Siso-Terraza P, Sudre D, Saviron M, Reyt G, Gaymard F, Abadia A, Abadia J, Alvarez-Fernandez A, Briat JF (2014) Involvement of the ABCG37 transporter in secretion of scopoletin and derivatives by Arabidopsis roots in response to iron deficiency. New Phytol 201:155-167

Frazzon AP, Ramirez MV, Warek U, Balk J, Frazzon J, Dean DR, Winkel BS (2007) Functional analysis of Arabidopsis genes involved in mitochondrial iron-sulfur cluster assembly. Plant Mol Biol 64:225-240

Garcia MJ, Romera FJ, Stacey MG, Stacey G, Villar E, Alcantara E, Perez-Vicente R (2013) Shoot to root communication is necessary to control the expression of iron-acquisition genes in Strategy I plants. Planta 237:65-75

Garcia-Mina JM, Bacaicoa E, Fuentes M, Casanova E (2013) Fine regulation of leaf iron use efficiency and iron root uptake under limited iron bioavailability. Plant Sci 198:39-45

Gerber J, Muhlenhoff U, Lill R (2003) An interaction between frataxin and Isu1/Nfs1 that is crucial for Fe/S cluster synthesis on Isu1. EMBO Rep 4:906-911

Giehl RF, Lima JE, von Wiren N (2012) Localized iron supply triggers lateral root elongation in Arabidopsis by altering the AUX1mediated auxin distribution. Plant Cell 24:33-49

Green LS, Rogers EE (2004) FRD3 controls iron localization in Arabidopsis. Plant Physiol 136:2523-2531

Grillet L, Mari S, Schmidt W (2014) Iron in seeds-loading pathways and subcellular localization. Front Plant Sci 4:535

Hagelueken G, Wiehlmann L, Adams TM, Kolmar H, Heinz DW, Tummler B, Schubert WD (2007) Crystal structure of the electron transfer complex rubredoxin rubredoxin reductase of Pseudomonas aeruginosa. Proc Natl Acad Sci USA 104:12276-12281

Hindt MN, Guerinot ML (2012) Getting a sense for signals: regulation of the plant iron deficiency response. Biochim Biophys Acta 1823:1521-1530

Ivanov R, Brumbarova T, Bauer P (2012) Fitting into the harsh reality: regulation of iron-deficiency responses in dicotyledonous plants. Mol Plant 5:27-42

Jakoby M, Wang HY, Reidt W, Weisshaar B, Bauer P (2004) FRU (BHLH029) is required for induction of iron mobilization genes in Arabidopsis thaliana. FEBS Lett 577:528-534

Johnson DC, Dean DR, Smith AD, Johnson MK (2005) Structure, function, and formation of biological iron-sulfur clusters. Annu Rev Biochem 74:247-281

Kaplan CD, Kaplan J (2009) Iron acquisition and transcriptional regulation. Chem Rev 109:4536-4552

Kim R, Saxena S, Gordon DM, Pain D, Dancis A (2001) J-domain protein, Jac1p, of yeast mitochondria required for iron homeostasis and activity of $\mathrm{Fe}-\mathrm{S}$ cluster proteins. J Biol Chem 276:17524-17532

Kispal G, Csere P, Prohl C, Lill R (1999) The mitochondrial proteins Atm $1 p$ and Nfs $1 p$ are essential for biogenesis of cytosolic $\mathrm{Fe} / \mathrm{S}$ proteins. EMBO J 18:3981-3989

Klatte M, Schuler M, Wirtz M, Fink-Straube C, Hell R, Bauer P (2009) The analysis of Arabidopsis nicotianamine synthase mutants reveals functions for nicotianamine in seed iron loading and iron deficiency responses. Plant Physiol 150:257-271

Koen E, Besson-Bard A, Duc C, Astier J, Gravot A, Richaud P, Lamotte O, Boucherez J, Gaymard F, Wendehenne D (2013) Arabidopsis thaliana nicotianamine synthase 4 is required for proper response to iron deficiency and to cadmium exposure. Plant Sci 209:1-11

Kushnir S, Babiychuk E, Storozhenko S, Davey MW, Papenbrock J, De Rycke R, Engler G, Stephan UW, Lange H, Kispal G, Lill R, 
Van Montagu M (2001) A mutation of the mitochondrial ABC transporter Sta1 leads to dwarfism and chlorosis in the Arabidopsis mutant starik. Plant Cell 13:89-100

Laemmli UK (1970) Cleavage of structural proteins during the assembly of the head of bacteriophage T4. Nature 227:680-685

Leaden L, Busi MV, Gomez-Casati DF (2014) The mitochondrial proteins AtHscB and AtIsul involved in Fe-S cluster assembly interact with the Hsp70-type chaperon AtHscA2 and modulate its catalytic activity. Mitochondrion 19(Pt B):375-381

Lee JW, Helmann JD (2007) Functional specialization within the Fur family of metalloregulators. Biometals 20:485-499

Li L, Miao R, Bertram S, Jia X, Ward DM, Kaplan J (2012) A role for iron-sulfur clusters in the regulation of transcription factor Yap5dependent high iron transcriptional responses in yeast. J Biol Chem 287:35709-35721

Liang X, Qin L, Liu P, Wang M, Ye H (2014) Genes for iron-sulphur cluster assembly are targets of abiotic stress in rice, Oryza sativa. Plant Cell Environ 37:780-794

Lichtenthaler HK (1987) Chlorophylls and carotenoids: pigments of photosynthetic biomembranes. Methods Enzymol 148:350-382

Lill R (2009) Function and biogenesis of iron-sulphur proteins. Nature 460:831-838

Lill R, Muhlenhoff U (2008) Maturation of iron-sulfur proteins in eukaryotes: mechanisms, connected processes, and diseases. Annu Rev Biochem 77:669-700

Lill R, Hoffmann B, Molik S, Pierik AJ, Rietzschel N, Stehling O, Uzarska MA, Webert H, Wilbrecht C, Muhlenhoff U (2012) The role of mitochondria in cellular iron-sulfur protein biogenesis and iron metabolism. Biochim Biophys Acta 1823:1491-1508

Lisec J, Schauer N, Kopka J, Willmitzer L, Fernie AR (2006) Gas chromatography mass spectrometry-based metabolite profiling in plants. Nat Protoc 1:387-396

Long TA, Tsukagoshi H, Busch W, Lahner B, Salt DE, Benfey PN (2010) The bHLH transcription factor POPEYE regulates response to iron deficiency in Arabidopsis roots. Plant Cell 22:2219-2236

Lopez-Millan AF, Morales F, Abadia A, Abadia J (2000) Effects of iron deficiency on the composition of the leaf apoplastic fluid and xylem sap in sugar beet. Implications for iron and carbon transport. Plant Physiol 124:873-884

Lucena C, Waters BM, Romera FJ, Garcia MJ, Morales M, Alcantara E, Perez-Vicente R (2006) Ethylene could influence ferric reductase, iron transporter, and H+-ATPase gene expression by affecting FER (or FER-like) gene activity. J Exp Bot 57:4145-4154

Lucena C, Romera FJ, Garcia MJ, Alcantara E, Perez-Vicente R (2015) Ethylene participates in the regulation of Fe deficiency responses in Strategy I plants and in rice. Front Plant Sci 6:1056

Maas FM, van de Wetering DA, van Beusichem ML, Bienfait HF (1988) Characterization of phloem iron and its possible role in the regulation of Fe-efficiency reactions. Plant Physiol 87:167-171

Maio N, Singh A, Uhrigshardt H, Saxena N, Tong WH, Rouault TA (2014) Cochaperone binding to LYR motifs confers specificity of iron sulfur cluster delivery. Cell Metab 19:445-457

Maliandi MV, Busi MV, Clemente M, Zabaleta EJ, Araya A, GomezCasati DF (2007) Expression and one-step purification of recombinant Arabidopsis thaliana frataxin homolog (AtFH). Protein Expr Purif 51:157-161

Maliandi MV, Busi MV, Turowski VR, Leaden L, Araya A, GomezCasati DF (2011) The mitochondrial protein frataxin is essential for heme biosynthesis in plants. FEBS J 278:470-481

Markley JL, Kim JH, Dai Z, Bothe JR, Cai K, Frederick RO, Tonelli M (2013) Metamorphic protein IscU alternates conformations in the course of its role as the scaffold protein for iron-sulfur cluster biosynthesis and delivery. FEBS Lett 587:1172-1179

Martin M, Colman MJ, Gomez-Casati DF, Lamattina L, Zabaleta EJ (2009) Nitric oxide accumulation is required to protect against iron-mediated oxidative stress in frataxin-deficient Arabidopsis plants. FEBS Lett 583:542-548

Morrissey J, Baxter IR, Lee J, Li L, Lahner B, Grotz N, Kaplan J, Salt DE, Guerinot ML (2009) The ferroportin metal efflux proteins function in iron and cobalt homeostasis in Arabidopsis. Plant Cell 21:3326-3338

Msilini N, Essemine J, Zaghdoudi M, Harnois J, Lachaal M, Ouerghi Z, Carpentier R (2013) How does iron deficiency disrupt the electron flow in photosystem I of lettuce leaves? J Plant Physiol 170:1400-1406

Muhlenhoff U, Lill R (2000) Biogenesis of iron-sulfur proteins in eukaryotes: a novel task of mitochondria that is inherited from bacteria. Biochim Biophys Acta 1459:370-382

Nikolic M, Romheld V (2003) Nitrate does not result in iron inactivation in the apoplast of sunflower leaves. Plant Physiol 132:1303-1314

Pastore A, Puccio H (2013) Frataxin: a protein in search for a function. J Neurochem 126(Suppl 1):43-52

Petit JM, Briat JF, Lobreaux S (2001) Structure and differential expression of the four members of the Arabidopsis thaliana ferritin gene family. Biochem J 359:575-582

Pfaffl MW (2001) A new mathematical model for relative quantification in real-time RT-PCR. Nucleic Acids Res 29:e45

Poor CB, Wegner SV, Li H, Dlouhy AC, Schuermann JP, Sanishvili R, Hinshaw JR, Riggs-Gelasco PJ, Outten CE, He C (2014) Molecular mechanism and structure of the Saccharomyces cerevisiae iron regulator Aft2. Proc Natl Acad Sci USA 111:4043-4048

Ravet K, Touraine B, Boucherez J, Briat JF, Gaymard F, Cellier F (2009) Ferritins control interaction between iron homeostasis and oxidative stress in Arabidopsis. Plant J 57:400-412

Reyt G, Boudouf S, Boucherez J, Gaymard F, Briat JF (2015) Iron- and ferritin-dependent reactive oxygen species distribution: impact on Arabidopsis root system architecture. Mol Plant 8:439-453

Robinson NJ, Procter CM, Connolly EL, Guerinot ML (1999) A ferricchelate reductase for iron uptake from soils. Nature 397:694-697

Rodriguez-Celma J, Schmidt W (2013) Reduction-based iron uptake revisited: on the role of secreted iron-binding compounds. Plant Signal Behav 8:e26116

Rodriguez-Lucena P, Tomasi N, Pinton R, Hernández Apaolaza L, Lucena JJ, Cesco S (2009) Evaluation of 59Fe-lignosulfonates complexes as Fe-sources for plants. Plant Soil 325:53-63

Rogers EE, Guerinot ML (2002) FRD3, a member of the multidrug and toxin efflux family, controls iron deficiency responses in Arabidopsis. Plant Cell 14:1787-1799

Roosta HR, ohsenian Y (2012) Effects of foliar spray of different Fe sources on pepper (Capsicum annum L.) plants in aquaponic system. Sci Hortic 146:182-191

Roschzttardtz H, Conejero G, Curie C, Mari S (2009) Identification of the endodermal vacuole as the iron storage compartment in the Arabidopsis embryo. Plant Physiol 151:1329-1338

Roschzttardtz H, Grillet L, Isaure MP, Conejero G, Ortega R, Curie C, Mari S (2011) Plant cell nucleolus as a hot spot for iron. J Biol Chem 286:27863-27866

Roschzttardtz H, Seguela-Arnaud M, Briat JF, Vert G, Curie C (2011) The FRD3 citrate effluxer promotes iron nutrition between symplastically disconnected tissues throughout Arabidopsis development. Plant Cell 23:2725-2737

Rubio V, Shen Y, Saijo Y, Liu Y, Gusmaroli G, Dinesh-Kumar SP, Deng XW (2005) An alternative tandem affinity purification strategy applied to Arabidopsis protein complex isolation. Plant J 41:767-778

Santi S, Schmidt W (2009) Dissecting iron deficiency-induced proton extrusion in Arabidopsis roots. New Phytol 183:1072-1084

Schmidt W (2003) Iron solutions: acquisition strategies and signaling pathways in plants. Trends Plant Sci 8:188-193 
Schmidt W, Buckhout TJ (2011) A hitchhiker's guide to the Arabidopsis ferrome. Plant Physiol Biochem 49:462-470

Selote D, Samira R, Matthiadis A, Gillikin JW, Long TA (2015) Ironbinding E3 ligase mediates iron response in plants by targeting basic helix-loop-helix transcription factors. Plant Physiol 167:273-286

Sieker LC, Stenkamp RE, Jensen LH, Prickril B, LeGall J (1986) Structure of rubredoxin from the bacterium Desulfovibrio desulfuricans. FEBS Lett 208:73-76

Sivitz AB, Hermand V, Curie C, Vert G (2012) Arabidopsis bHLH100 and bHLH101 control iron homeostasis via a FIT-independent pathway. PLoS One 7:e44843

Stemmler TL, Lesuisse E, Pain D, Dancis A (2010) Frataxin and mitochondrial FeS cluster biogenesis. J Biol Chem 285:26737-26743

Steuer R, Nesi AN, Fernie AR, Gross T, Blasius B, Selbig J (2007) From structure to dynamics of metabolic pathways: application to the plant mitochondrial TCA cycle. Bioinformatics 23:1378-1385

Tarantino D, Santo N, Morandini P, Casagrande F, Braun HP, Heinemeyer J, Vigani G, Soave C, Murgia I (2010) AtFer4 ferritin is a determinant of iron homeostasis in Arabidopsis thaliana heterotrophic cells. J Plant Physiol 167:1598-1605

Tripodi KEJ, Podestá FE (2003) Purification and characterization of an NAD-dependent malate dehydrogenase from leaves of the crassulacean acid metabolism plant Aptenia cordifolia. Plant Physiol Biochem 41:97-105

Turowski VR, Busi MV, Gomez-Casati DF (2012) Structural and functional studies of the mitochondrial cysteine desulfurase from Arabidopsis thaliana. Mol Plant 5:1001-1010

Uhrigshardt H, Singh A, Kovtunovych G, Ghosh M, Rouault TA (2010) Characterization of the human HSC20, an unusual DnaJ type III protein, involved in iron-sulfur cluster biogenesis. Hum Mol Genet 19:3816-3834

Vert G, Grotz N, Dedaldechamp F, Gaymard F, Guerinot ML, Briat JF, Curie C (2002) IRT1, an Arabidopsis transporter essential for iron uptake from the soil and for plant growth. Plant Cell $14: 1223-1233$

Vert GA, Briat JF, Curie C (2003) Dual regulation of the Arabidopsis high-affinity root iron uptake system by local and long-distance signals. Plant Physiol 132:796-804

Vigani G (2012) Discovering the role of mitochondria in the iron deficiency-induced metabolic responses of plants. J Plant Physiol 169:1-11

Vigani G, Maffi D, Zocchi G (2009) Iron availability affects the function of mitochondria in cucumber roots. New Phytol 182:127-136

Vigani G, Zocchi G, Bashir K, Philippar K, Briat JF (2013) Signals from chloroplasts and mitochondria for iron homeostasis regulation. Trends Plant Sci 18:305-311

Xu XM, Lin H, Latijnhouwers M, Moller SG (2009) Dual localized AtHscB involved in iron sulfur protein biogenesis in Arabidopsis. PLoS One 4:e7662

Yi Y, Guerinot ML (1996) Genetic evidence that induction of root $\mathrm{Fe}(\mathrm{III})$ chelate reductase activity is necessary for iron uptake under iron deficiency. Plant J 10:835-844

Yuan Y, Wu H, Wang N, Li J, Zhao W, Du J, Wang D, Ling HQ (2008) FIT interacts with AtbHLH38 and AtbHLH39 in regulating iron uptake gene expression for iron homeostasis in Arabidopsis. Cell Res 18:385-397 